\title{
Material stone-concrete - selection of composition for concrete face rockfill dams
}

\author{
Alexandra Bestuzheva ${ }^{*}$, Ilya Tsipurskiy, and Dimitri Gadai \\ Moscow State University of Civil Engineering, Yaroslavskoe shosse, 26, Moscow, 129337, Russia
}

\begin{abstract}
The properties of the face zone material as a flexible foundation of the face play an extremely important role in the formation of stressstrain state of rockfill dams with reinforced concrete face. Stone-concrete, made by watering the stone backfill with cement-sand mix containing water-reducing agents is proposed to be used as such foundation in the paper. Methods of selecting the composition of the casting mixture and search results of its optimal composition by the method of factor analysis are given in this paper. The properties of stone-concrete are investigated and a dam design technique is developed based on the selection of optimal properties for the face zone of that material.
\end{abstract}

\section{Introduction}

Cost-effectiveness of rockfill dams with reinforced concrete face is undeniable, but the more strained are the properties of the stone backfill, the more acute is the problem of case cracking $[1,2]$. The solution of this problem often requires soil zoning of the dam body, including creation of a more durable and compact crush-stone or pebble shoulder in the face zone. An artificial transition zone (a shoulder), made by "fixing" gravel-pebbly and crush-stone soil backfill with gravitation cement-sand mix is proposed to be used in the paper. The resulting face zone is solid and can serve as a new line to protect the dam against through filtration in case of cracking in the reinforced concrete face. Face zone width varies based on the ability to fit cementing galleries, thus allows performing injection in the zone of cracking during repair and restoration works, and more importantly - without reservoir storage decrease, which is impossible for reservoirs with long-term regulation [3].

Stone-concrete is a material with low content of cement (not more than $80 \mathrm{~kg} / \mathrm{m}^{3}$ ). It is made by using the technique of preplaced gravitation concreting [4]. A layer of crush-stone or gravel fractions $(20-70 \mathrm{~mm})$ soil backfilled up to $0.5 \mathrm{~m}$ height is watered with cementsand mix, rich in mineral powder with high water/cement ratio $(\mathrm{W} / \mathrm{C}>2)$. The selection of casting mixture composition depends on backfill density and the required strength properties according to the methods developed by the authors of this paper. To select the optimal composition, it is necessary to meet the prescribed properties of the cement-sand mix such as apparent viscosity and stability. Any deviation from these properties can result in either a too thick mix that will not be able to fill the crush-stone backfill along the full

\footnotetext{
${ }^{*}$ Corresponding author: alex_bestu@ mail.ru
} 
height or a too liquid mix that will leak through the backfill and not fill its pores. Moreover, water bleeding of the casting mixture increases at high W/C ratio. Utilization of the attachable distribution equipment mounted on a concrete mixer truck that allows equal mixture distribution over 3-4 m width can optimize watering technique of the backfilled crush-stone layer.

\section{Methods}

Initial study involved selection of composition of the casting mixture meeting the prescribed strength, apparent viscosity and stability of the cement-sand mix [5]. This required:

- Definition of viscosity, water bleeding and strength of the casting mixture;

- Searching the optimal casting mixtures within the framework of multi-factor optimization method;

- Determining the dependencies of that allow predicting of the casting mixture properties.

Optimization of the casting mixture composition for stone-concrete was carried out as part of factor analysis with the matrix plan $3^{3}$, whose regression equations, according to the earlier studies, more adequately describe the given material [6]. Table 1 shows factors and levels of their variation per $1 \mathrm{~m}^{3}$ of stone-concrete.

Table 1. Factors and Levels of Their Variation.

\begin{tabular}{|l|c|c|c|c|}
\hline \multirow{2}{*}{ Factors } & \multirow{2}{*}{ Identification } & \multicolumn{3}{|c|}{ Variation levels, $\left(\mathrm{kg} / \mathrm{m}^{3}\right.$ of stone-concrete $)$} \\
\cline { 3 - 5 } & & Lower $(-1)$ & Basic $(0)$ & Upper $(+1)$ \\
\hline Cement content, C & $\mathrm{X}_{1}$ & 50 & 75 & 100 \\
\hline Sand content, S & $\mathrm{X}_{2}$ & 200 & 300 & 400 \\
\hline Mineral powder content, MP & $\mathrm{X}_{3}$ & 100 & 175 & 250 \\
\hline
\end{tabular}

The mineral powder MP was used to reduce water bleeding of the mixture. This is a product of limestone, dolomite, dolomitized limestone, smelter slag, and some other materials $(70 \%$ of particles $<71 \mu \mathrm{m})$ fine grinding. Its main component is calcium carbonate. Utilization of such mineral additives does not harm the environment and can be used in waterworks construction.

To find the optimal composition of a casting mixture for stone-concrete involved searching for the composition, which has a minimum cost (target function - the cost of casting mixture, 1 liter) and conforms to prescribed parameters - limitations of the prescribed properties. The limitation functions were assumed as follows:

- technological function - apparent viscosity of the casting mixture;

- technological and quality function- stability of the casting mixture, controlled by MP admixtures;

- strength function - cube strength of the casting mixture with 28-days old $100 \mathrm{~mm}$ face.

Twenty seven compositions of the casting mixture with different content of cement (C), sand (S) and mineral powder (MP) were composed within the framework of the full-factor analysis $3^{3}$. Figure 1 shows the graphical representation of the plan $3^{3}$ with the experiment number and level indication. 


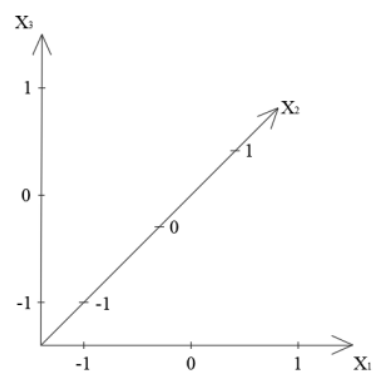

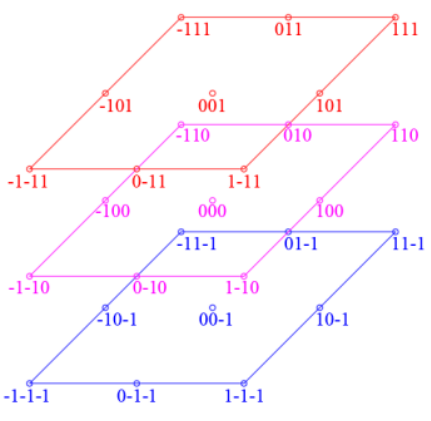

a)

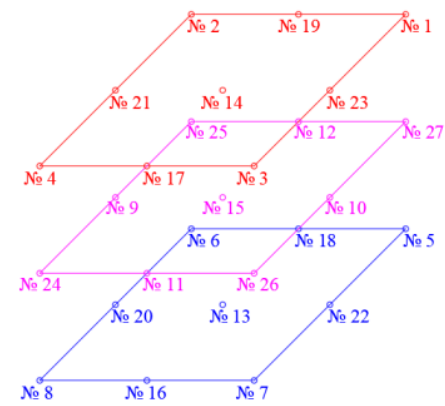

b)

Fig. 1. Graphical representation of the matrix plan $3^{3}$

$\mathrm{a}$ - according to factor levels, $\mathrm{b}$ - according to the number of the casting mixture compositions.

Each composition was tested twice and the parameters of apparent viscosity (sec) on the standard VZ-246 viscometer with a nozzle diameter of $6 \mathrm{~mm}$, disintegration (\%) of the size of the layer of separated water for 5, 10 and 20 minutes and cube strength on uniaxial compression (MPa) were prescribed for each composition. The conducted studies were systematized in order to identify correlations between the quantitative relationships of the ingredients of the casting mixture and its controlled properties. Note that in our experiments the conditional viscosity parameter was determined in seconds, according to the time of spilling a portion of the casting mixture through the viscometer nozzle. Setting the range of permissible parameters of the viscosity of the casting mixture was carried out in the course of test spills of crushed limestone dumping $0.5 \mathrm{~m}$ in height with compositions of different viscosity. Dependency graphs were drawn up to predict viscosity (Figure 2), water bleeding (Figure 3), and strength (Figure 4) using W/(C+S+MP), W/(C+MP) and W/C ratios, where $\mathrm{W}$ is water, $1 / \mathrm{m}^{3}, \mathrm{C}$ is cement, $\mathrm{kg} / \mathrm{m}^{3}$, and $\mathrm{S}$ is sand, $\mathrm{kg} / \mathrm{m}^{3}$.

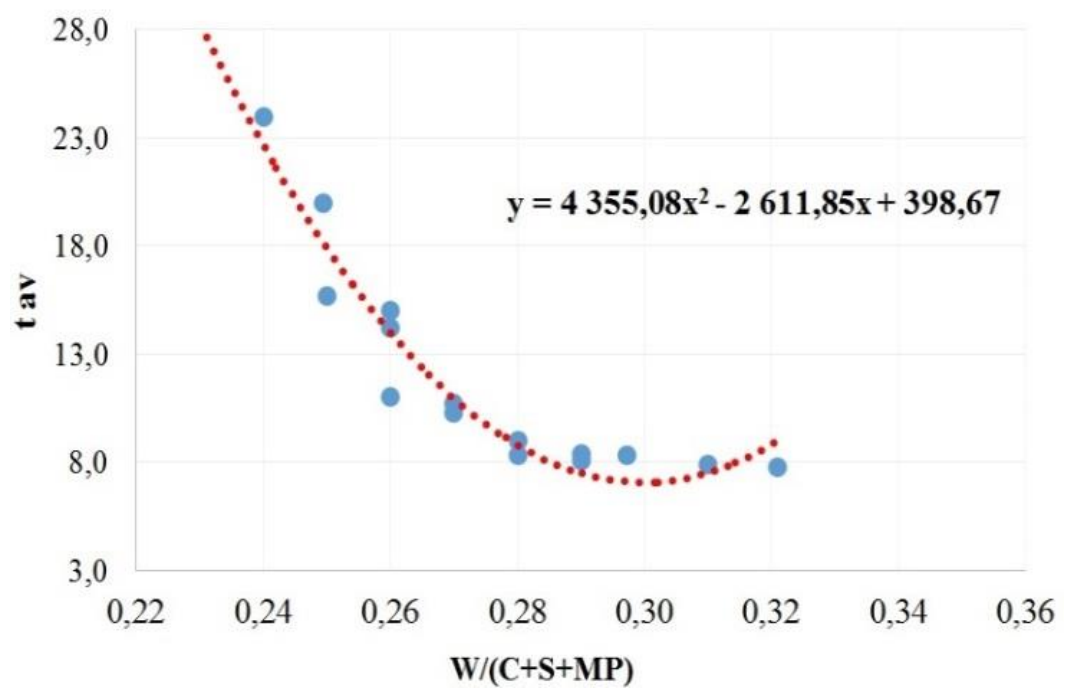

Fig. 2. Graph for the viscosity function. 


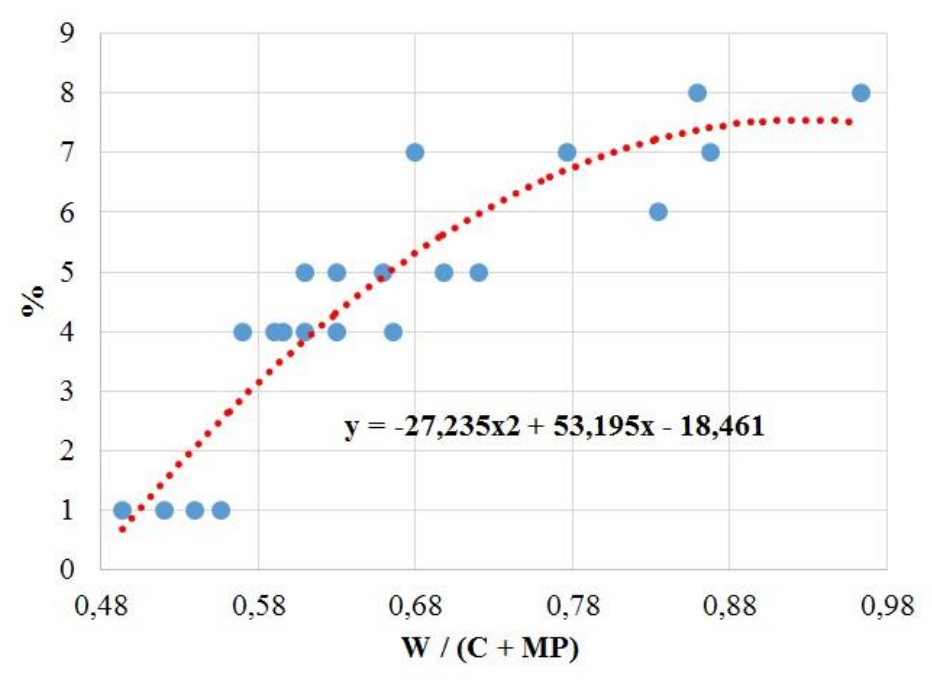

Fig. 3. Graph for the water bleeding.

Compositions with MP content $=100 \mathrm{~kg} / \mathrm{m}^{3}$ and MP content $=175 \mathrm{~kg} / \mathrm{m}^{3}$ do not comply with the limitation functions for viscosity and water bleeding (water bleeding for such mixtures is in the range of $17-50 \%$, with a limit of $5 \%$ ) even with acceptable cube strength. Thus, within the framework of this experiment it is recommended to use a curve corresponding to the MP content $=250 \mathrm{~kg}$ for $1 \mathrm{~m}^{3}$ of stone-concrete on the strength function graph (Figure 4).

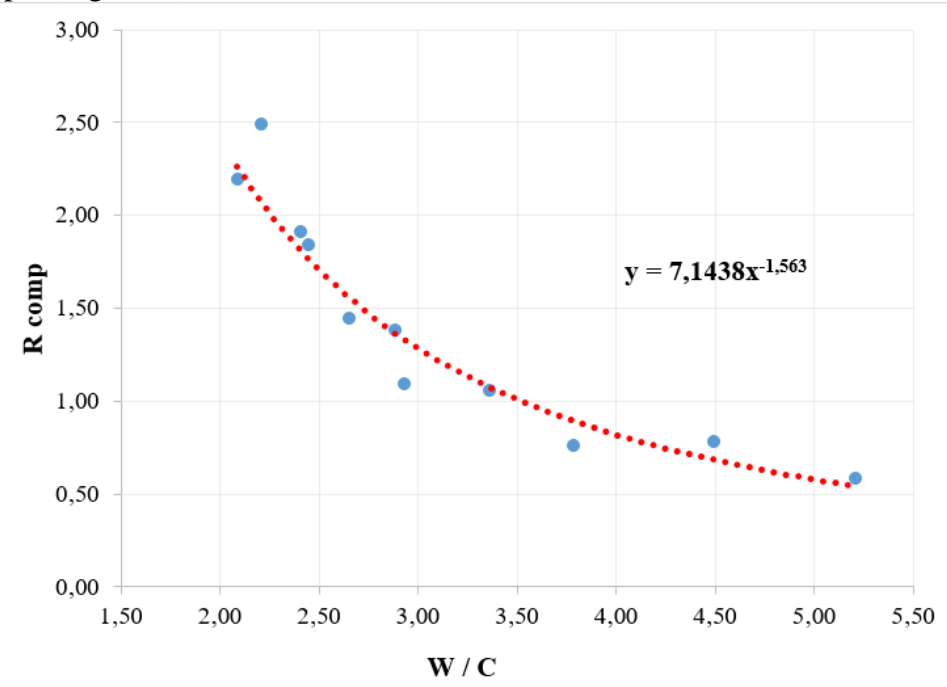

Fig. 4. Graph for the strength function with content of the $\mathrm{MP}=250 \mathrm{~kg} / \mathrm{m}^{3}$

Samples with different compositions of the casting mixture were tested according to the matrix plan (40 different compositions and more than 120 tests in total). Regression equations were written for all criteria functions of the casting mixture based on the test results.

Minimizing the target function of the cost of $1 \mathrm{~m} 3$ of stone-concrete under the conditions of meeting the limitation criteria for each function allowed to obtain the optimal 
solution of the casting mixture (See Table 2) and to select the compositions (close to the optimal solution), that were later used for stone-concrete manufacture.

Table 2. Optimal properties of casting mixture composition.

\begin{tabular}{|c|c|c|c|c|c|c|c|c|c|c|}
\hline \multirow[t]{2}{*}{ № } & \multicolumn{3}{|c|}{ Factors } & \multicolumn{4}{|c|}{$\begin{array}{c}\text { Composition for } 1 \mathrm{~m}^{3} \text { of stone- } \\
\text { cement }\end{array}$} & \multirow{2}{*}{ 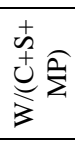 } & \multirow{2}{*}{ 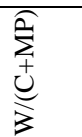 } & \multirow[t]{2}{*}{$\mathrm{W} / \mathrm{C}$} \\
\hline & $\mathrm{X}_{1}$ & $\mathrm{X}_{2}$ & $\mathrm{X}_{3}$ & $\mathrm{C}, \mathrm{kg}$ & $\mathrm{S}, \mathrm{kg}$ & $\begin{array}{c}\mathrm{MP}, \\
\mathrm{kg}\end{array}$ & $\mathrm{W}, 1$ & & & \\
\hline Optimal & -0.275 & 1 & 0.927 & 68 & 400 & 245 & 184 & 0.26 & 0.59 & 2.71 \\
\hline
\end{tabular}

Validation for adequacy of the obtained regression equations for viscosity $f$, water bleeding, and axial compression strength functions (required additional "calibration" tests) showed their sufficient accuracy, the maximum discrepancy does not exceed $7 \%$.

Stone-concrete samples with $20 \ldots 40 \mathrm{~mm}$ crushed limestone aggregate were tested, and the composition of the casting mixture on the basis of the matrix plan of factor analysis $3^{3}$ was calculated at the second stage of this study [5, 7]. Such tests allowed comparing strength function parameters of the casting mixture with stone-concrete samples filled with the cement-sand mix of the same composition. The size of the cube face required to determine the cube strength of the stone-concrete had to be increased to $200 \mathrm{~mm}$.

\section{Results}

Studies of the strength and strain properties of the casting mixture and stone-concrete samples were carried out in Construction, Materials, Products and Structures Testing Laboratory of the Center of Shared Usage of Equipment NRU MGSU [8].

The produced samples (cubes and prisms) of stone-concrete were tested to obtain cube and prism strength parameters (Figure 5) as well as elasticity modulus (Figure 6) and stressstrains modulus.

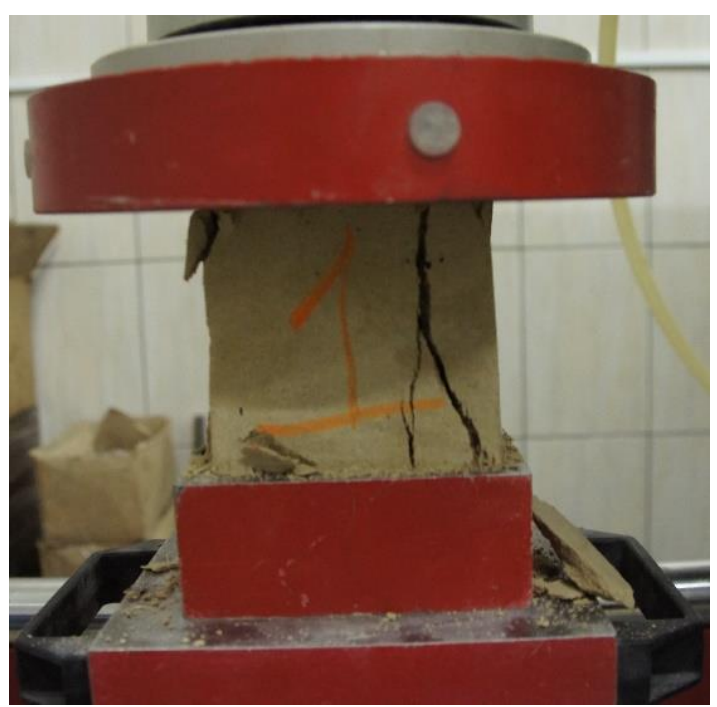

Fig. 5. Definition of stone-concrete cube strength.

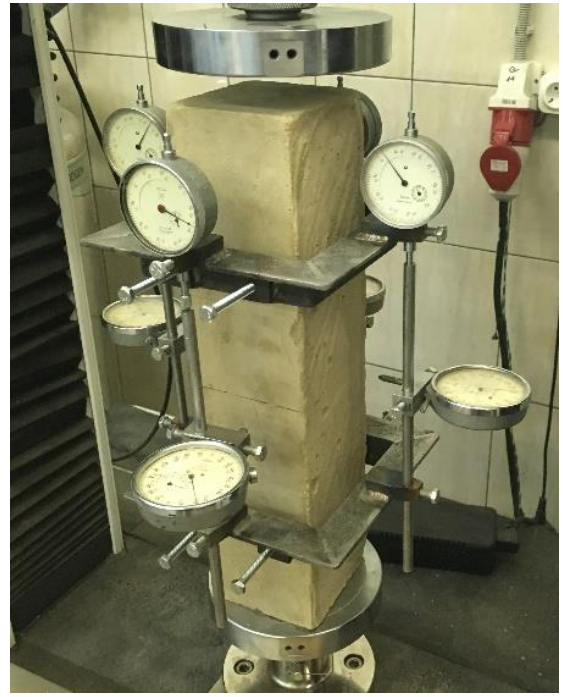

Fig. 6. Definition of elasticity modulus of stone-concrete.

The comparison of strength and elasticity parameters of the casting mixture with the same properties of the stone-concrete but filled with the same casting mixture composition 
allowed correlation of casting mixture test results with the strength and elasticity data of stone-concrete. These results of optimal solution for stone-concrete compositions are given in Table 3.

Table 3. Physical and mechanical properties of casting mixture and stone-concrete.

\begin{tabular}{|l|c|c|c|c|}
\hline \multicolumn{1}{|c|}{ Material } & Density, $\rho$ & $\begin{array}{c}\text { Cube strength, } \\
\text { Rcomp }\end{array}$ & $\begin{array}{c}\text { Prism strength, } \\
\text { Rstr }\end{array}$ & $\begin{array}{c}\text { Elasticity } \\
\text { modulus, E }\end{array}$ \\
\cline { 2 - 5 } & $\mathrm{t} / \mathrm{m}^{3}$ & MPa & MPa & MPa \\
\hline $\begin{array}{l}\text { Casting } \\
\text { mixture }\end{array}$ & 1.97 & 1.6 & 1.3 & 1840 \\
\hline Stone-concrete & 2.06 & 2.2 & 1.8 & 6730 \\
\hline
\end{tabular}

Analysis of these results shows that strength properties of stone-concrete are more than 1.4-1.5 times higher than the same properties of the casting mixture. The same ratio was obtained for cube and prism strength of the samples, and the elasticity modulus of stoneconcrete is 3.6 times higher than the elasticity of the casting mixture.

The average density of stone-concrete in the conducted studies was $2.06 \mathrm{t} / \mathrm{m}^{3}$, and the density of the casting mixture was $1.97 \mathrm{t} / \mathrm{m}^{3}$.

The resulted cube strength/prism strength ratio $\left(\mathrm{R}_{\mathrm{str}} \approx 0,8 \cdot \mathrm{R}_{\text {comp }}\right)$ of stone-concrete, as well as elasticity modulus/ cube strength ratio $\left(E \approx 3000 \cdot \mathrm{R}_{\mathrm{c} \kappa}\right)$ are comparable to the criteria obtained by calculation formulas in L.I. Dvorkina's papers [9, p. 14] for cast concrete.

\section{Discussion}

An algorithm of the casting mixture selection was formed after analyzing and structuring of the obtained data (see Figure 7).

Boundary conditions of the algorithm were defined before starting the selection of stone-concrete compositions. As shown by the authors of these studies $[5,7,11]$, the elasticity modulus of the optimal stone-concrete composition, calculated for the specific material performance conditions in the dam face zone, varies in the range of $4000 \div 8000$ $\mathrm{MPa}$. The accepted «operating range» of stone-concrete compositions complies with the variation range of the material properties from $2 \mathrm{MPa}$ to $4 \mathrm{MPa}$. To produce a casting mixture with the required stress-related properties it is necessary to know its composition, namely, quantitative values of its components: cement (C), sand (S), mineral powder (MP), and water (W). The porosity of the crush-stone (n) based on experimental backfills and with calculation methods based on its grain size composition has to be defined before starting the selection process. 


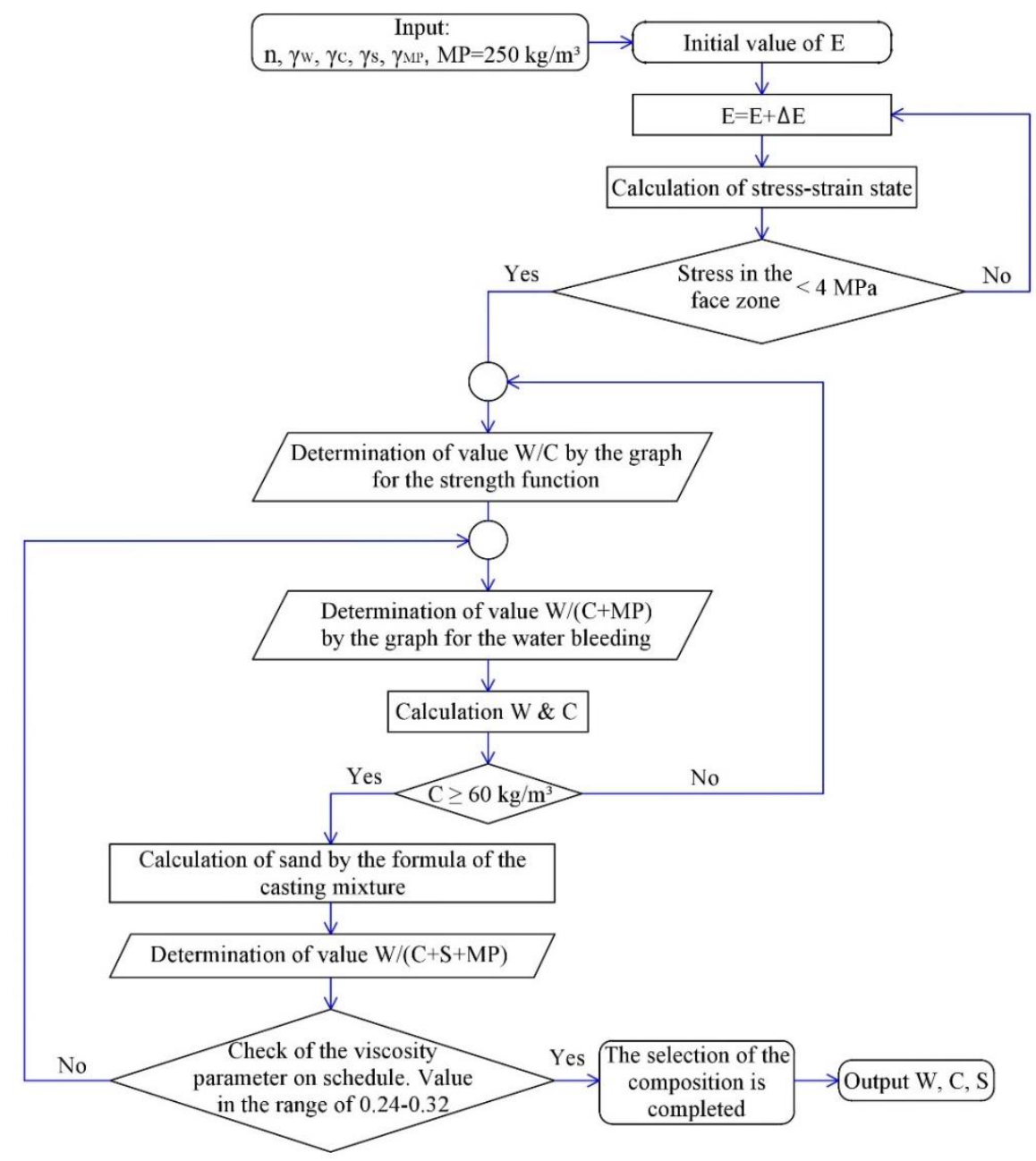

Fig. 7. Algorithm for selecting the composition of stone-concrete.

Methods of selection of stone-concrete can be described by the following algorithm:

1. Stress-strain state of the dam with reinforced concrete face and stone-concrete face zone with elasticity modulus of the face zone at its minimum value $E_{\text {initial }}=4000$ $\mathrm{MPa}$ is calculated at the initial stage. The selection process starts if the axial compression strength of the face zone exceeds $4 \mathrm{MPa}$; if it does not, then it is necessary to return to the initial stage and adopt a higher elasticity modulus with a certain step, which means to make stone-concrete with enhanced strength properties.

2. According to the strength (Figure 4) and water bleeding (Figure 3) graphs the W/C and $\mathrm{W} /(\mathrm{C}+\mathrm{MP})$ ratios that correspond to the initial conditions of the acceptable criteria of the casting mixture were adopted. Known MP value $\left(250 \mathrm{~kg} / \mathrm{m}^{3}\right)$ and known initial values of the above-mentioned ratios allow determining cement and water weight for $1 \mathrm{~m}^{3}$ of stone-concrete in the process of the equation system solution:

$$
\left\{\begin{array}{c}
\frac{W}{C}=x \\
\frac{W}{C+M P}=y
\end{array}\right.
$$


3. If the amount of cement $\mathrm{C}$ is less than $60 \mathrm{~kg}$ for $1 \mathrm{~m}^{3}$ of stone-concrete, then a new 'y' value has to be adopted from the water bleeding graph (Figure 3), due to the fact that no experiments were performed for particularly lean concrete with high $\mathrm{W} / \mathrm{C}$ ratio.

4. The weight of the third solid component of the mixture - sand (S) is obtained by the following formula:

$$
S=\gamma_{S} \cdot\left(n-\frac{W}{\gamma_{W}}-\frac{C}{\gamma_{C}}-\frac{M P}{\gamma_{M P}}\right)
$$

where, $\gamma_{\mathrm{s}}, \gamma_{\mathrm{w}}, \gamma_{\mathrm{c}}, \gamma_{\mathrm{mp}}-$ the specific gravity of sand, water, cement and mineral powder (determined in laboratory conditions)

5. The watering function and elasticity modulus of all components of the obtained mixture is checked as shown on the graph (Figure 2);

$$
0.24 \leq \frac{W}{C+S+M P} \leq 0.32
$$

6. If the watering requirement is not met, then it is necessary to return to point 2 , change the initial $\mathrm{W} / \mathrm{C}$ ratio and water bleeding values of the mixture

Based on this algorithm (Figure 7), the authors wrote a certified computer program called "Selection stone-concrete". This program allows composing several different casting mixtures within the range of acceptable limitation criteria. The composition may be selected from among the proposed mixtures based on the stone-concrete work experience, cost or any other factors.

The proposed method was implemented in a test example for calculating the stressstrain state of a $100 \mathrm{~m}$ high rockfill dam with reinforced concrete face and stone-concrete face zone. The problem of the plane stress-strain state of a dam was solved by using 3D eight-unit finite elements. Face zone width varied between 35 to $70 \mathrm{~m}$ at foundation, and elasticity modulus of stone-concrete varied in the range of values obtained during these studies between $4000 \mathrm{MPa}$ to $8000 \mathrm{MPa}$. Elastic properties of stone-concrete were given taking in consideration the acceptable cracking, which were justified by the absence of requirements for waterproof material due to the presence of the main anti-filtration element - reinforced concrete-face in the dam. Stone-concrete as a "transition" layer between the crush-stone backfill and cast concrete has dual properties. It performs as concrete in low stress areas, exhibiting elastic properties, whereas in high stress areas stone-concrete exhibits nonlinear properties, it serves as a stone backfill, whose strain modulus increases as far as the effective stress increases and the ultimate strength corresponds to the crushing force of crush-stone. The key point of stone-concrete lies in the fact that at stress exceeding the limit of compression strength the material does not stop working but starts straining as a tightly compacted crush-stone backfill.

The calculation was carried out with regard to the sequence of a dam construction and the stages of reservoir filling. The soil model developed by Professor L.N. Rasskazov and later called the "energetic" soil model was used to account for nonlinear strain properties of the soil [12]. The program complex "Statdam_best" (Object Pascal-Delphi) was designed by the Department of Hydraulics and Hydrotechnical engineering NRU MGSU led by associate professor A.C. Bestuzheva under supervision of L.N. Rasskazov. The calculation algorithm of elastoplastic strain is based on the iterative searching for the minimum increment of total strain energy in the calculated area for every stage of load increment implemented by the method of local variations. The accuracy of the solution depends on the final iterative step, which equals $0.00002 \mathrm{~m}$ for the given solution. The method was developed by academician F.L. Chernousko [13] and was first implemented for backfill soil calculations by Professor L.N. Rasskazov in the 1970-s. 
The calculations showed that small tensile stress (up to $0.5 \mathrm{MPa}$ ) appears in the face zone contacting the face (in the upper third of the dam height). This stress increases with width and mass growth of the face zone (Figure 8). Such effect arising in all dam solutions with reinforced concrete face and is related to "hanging" of the face zone on a more solid and less strained reinforced concrete face. Friction forces keep the adjacent to the face zone stone-concrete if there is no sliding contact between them, thus making it interact with the reinforced concrete face. The tensile area in the stone-concrete may disappear if the possibility of the face zone slip along the inner edge is allowed.

An increase in the elasticity modulus of the face zone within the studied range $(6000$ $\mathrm{MPa}$ ) results in additional area of tensile stress on the border with the retaining prism, and though tensile stress does not exceed 0.5 MPa, the trend is obvious (Figure 9). The strengthening of the face zone requires soil zoning along the dam body in order to obtain the most favorable stress-strain state of the dam.

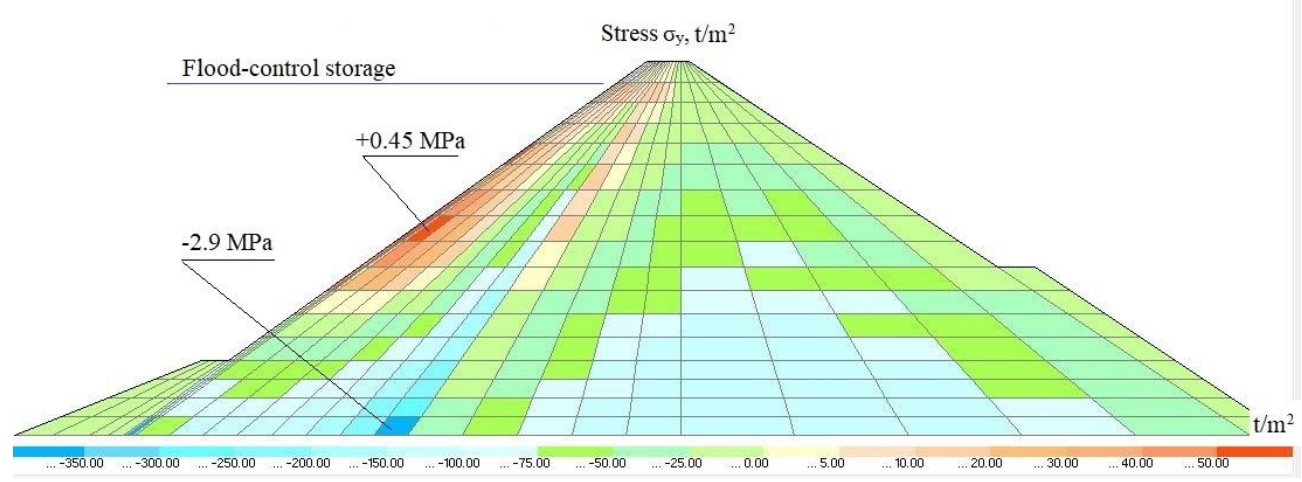

Fig.8. Stress distribution throughout the dam.

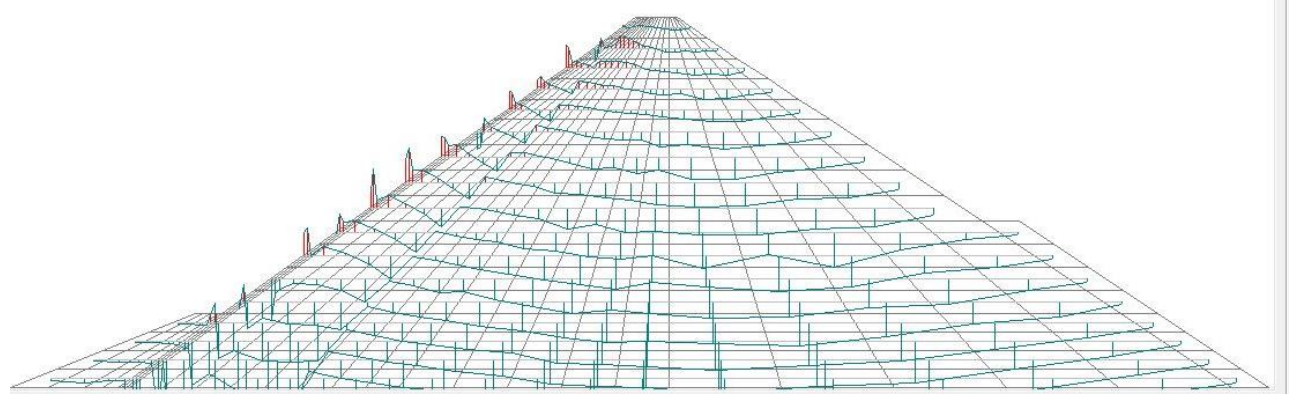

Fig. 9. Stress diagrams of the dam.

The calculation carried out with "Selection stone-concrete" program aimed at composition selection of the stone-concrete for the zone of compression strength up to $2 \mathrm{MPa}$ proposes several optimal compositions of the casting mixture (Table 4).

Table 4. Results of computer program selection.

\begin{tabular}{|c|c|c|c|c|c|}
\hline Option & Cement (C), kg & Sand (S), kg & W/C & W/(C+MP) & W/(C+S+MP) \\
\hline 1 & 76.57 & 418.70 & 2.26 & 0.530 & 0.23 \\
\hline 2 & 80.50 & 391.06 & 2.26 & 0.550 & 0.25 \\
\hline 3 & 85.41 & 355.59 & 2.26 & 0.575 & 0.28 \\
\hline
\end{tabular}




\section{Conclusions}

1. Selection of the composition for stone-concrete is recommended for the composition of the casting mixture with adjusted grain size composition of the stone backfill.

2. The main technological criteria of selecting the casting mixture is its viscosity and water bleeding.

3. $\mathrm{W} /(\mathrm{C}), \mathrm{W} /(\mathrm{C}+\mathrm{MP}), \mathrm{W} /(\mathrm{C}+\mathrm{S}+\mathrm{MP})$ ratios that are correlated with strength properties of the casting mixture for stone-concrete, the solution stability and viscosity, may be used to predict the properties of stone-concrete. The above-mentioned properties and the ranges of their acceptable values ensure adequate pores filling of crush-stone backfill during its gravity watering.

4. The proposed algorithm of selecting the casting mixture considers all possible component ratios and selects the components that meet the required viscosity, strength and stability properties. The proposed method facilitates to control face zone properties on order to create cost effective and technological solutions depending on specific construction conditions.

5. The studies of the stress-strained state of the dam with reinforced concrete face showed that with a significant difference between the strained properties of the face and the face zone, and lack of lubricant in contact between them, "hanging" of the face zone may occur on the face and lead to tensile stressing in the stone-concrete. Within the studied range of elasticity modulus $(4000-8000 \mathrm{MPa})$ stone-concrete elasticity does not exceed 0.5 MPa, but small tensile zones appear on the boarder of the solid stoneconcrete and strained retaining prism. Hence, it is recommended to utilize a wider solid zoning of over the dam body to improve its stress-strain state.

\section{References}

1. Y. Arici, Computers and Geotechnics, 38, 905-916 (2011).

2. M. Filho, P. De Pinto, International Journal on Hydropower and Dams, 12 (1), $72-76$ (2005).

3. W Song W, Y. Sun, Y. Wang, Journal of Hydroelectric Engineering, 3 (27), 33-37 (2008).

4. T A Zatvornitskaya, S A Konyaeva, B F Mikulovich, Cast Concrete in Hydraulic and Power Engineering. 112 (1974).

5. A. Bestuzheva, D. Gadai, Hydraulic Engineering, 10, 40-48 (2018)

6. A. Bestuzheva, D. Gadai, Power Technology and Engineering, T.51, No.4, 385-389 (2017).

7. A. Bestuzheva, D. Gadai, R. Sadekov, IOP Conf. Series: Materials Science and Engineering, Vol. 365 (2018).

8. Moscow State University of Civil Engineering - Construction Materials, Products and Structures Testing Laboratory of the Center of Shared Usage of Equipment http://isa.mgsu.ru/universityabout/Struktura/Instituti/ISA/nid/nauka/ekspertnodiagnosticheskiy-i-ispytatelnyy-tsentr-promyshlennoy-bezopasnosti.php

9. L. Dvorkin, V. Kizima. Effective Cast Concrete, 144 (1986).

10. L. Rasskazov. Trudi instituta VODGEO, 44, 53-59 (1974).

11. A. Bestuzheva, G. Bukanov. Hydraulic Engineering, 10, 34-38 (2016).

12. A. Goldin, L. Rasskazov, Proektirovanie gruntovix plotin. 384 (2001).

13. F. Chernousko, N. Banicuk, Variacionnie zadachi mexaniki i upravlenia, 240 (1973). 